\title{
Hepatic Tmem30a Deficiency Causes Intrahepatic Cholestasis by Impairing Expression and Localization of Bile Salt Transporters
}

\author{
Leiming Liu, ${ }^{\dagger \dagger}$ Lingling Zhang, ${ }^{\ddagger}$ Lin Zhang, ${ }^{\S \oplus}$ Fan Yang, ${ }^{\dagger \|}$ Xudong Zhu, ${ }^{\ddagger}$ Zhongjie Lu, ${ }^{* *}$ Yeming Yang, ${ }^{\S}$ Haiqi Lu, * \\ Lifeng Feng, ${ }^{*}$ Zhuo Wang, ${ }^{*}$ Hui Chen, ${ }^{* *}$ Sheng Yan, ${ }^{* *}$ Lin Wang, ${ }^{\dagger \dagger}$ Zhenyu Ju, ${ }^{\dagger \ddagger}$ Hongchuan Jin, ${ }^{*}$ and Xianjun Zhu ${ }^{\delta \oplus}$

\begin{abstract}
From the Laboratory of Cancer Biology,* Key Laboratory of Biotherapy in Zhejiang Province, Sir Runrun Shaw Hospital, and the Key Laboratory of Combined Multi-Organ Transplantation, ** Ministry of Public Health, Division of Hepatobiliary and Pancreatic Surgery, The First Affiliated Hospital, School of Medicine, Zhejiang University, Hangzhou, China; the Key Laboratory of Regenerative Medicine of Ministry of Education, ${ }^{\dagger}$ Institute of Aging and Regenerative Medicine, Jinan University, Guangzhou, China; the Institute of Aging Research, ${ }^{\ddagger}$ Leibniz Link Partner Group on Stem Cell Aging, School of Medicine, Hangzhou Normal University, Hangzhou, China; the Sichuan Provincial Key Laboratory for Human Disease Gene Study and School of Medicine, ${ }^{\S}$ Sichuan Academy of Medical Sciences and Sichuan Provincial People's Hospital, Chengdu, China; the Key Laboratory for NeuroInformation of Ministry of Education and Medicine Information Center, ${ }^{\top}$ School of Medicine, University of Electronic Science and Technology of China, Chengdu, China; the Leibniz Institute for Age Research - Fritz Lipmann Institute, ${ }^{\|}$Friedrich-Schiller University of Jena, Jena, Germany; and the Department of Hepato-Biliary Surgery, ${ }^{\dagger \dagger}$ Xijing Hospital, The Fourth Military Medical University, Xi'an, China
\end{abstract}

\author{
Accepted for publication \\ August 17, 2017. \\ Address correspondence to \\ Hongchuan Jin, M.D., Ph.D., \\ Laboratory of Cancer Biology, \\ Sir Runrun Shaw Hospital, \\ \#401, 3 E Qingchun Rd, Hang- \\ zhou, Zhejiang 310016, China; \\ or Xianjun Zhu, Ph.D., Key \\ Laboratory for Human Disease \\ Gene Study, Sichuan Academy \\ of Medical Sciences and \\ Sichuan Provincial People's \\ Hospital, 32\# W Sec 2, 1st Ring \\ Rd, Chengdu, Sichuan 610072, \\ China. E-mail: jinhc@zju.edu. \\ cn orxjzhu@uestc.edu.cn.
}

\begin{abstract}
Mutations in ATP8B1 or ATP11C (members of P4-type ATPases) cause progressive familial intrahepatic cholestasis type 1 in human or intrahepatic cholestasis in mice. Transmembrane protein 30A (TMEM30A), a $\beta$-subunit, is essential for the function of ATP8B1 and ATP11C. However, its role in the etiology of cholestasis remains poorly understood. To investigate the function of TMEM30A in bile salt (BS) homeostasis, we developed Tmem30a liver-specific knockout (LKO) mice. Tmem30a LKO mice experienced hyperbilirubinemia, hypercholanemia, inflammatory infiltration, ductular proliferation, and liver fibrosis. The expression and membrane localization of ATP8B1 and ATP11C were significantly reduced in Tmem30a LKO mice, which correlated with the impaired expression and localization of BS transporters, such as OATP1A4, OATP1B2, NTCP, BSEP, and MRP2. The proteasome inhibitor bortezomib partially restored total protein levels of BS transporters but not the localization of BS transporters in the membrane. Furthermore, the expression of nuclear receptors, including FXR $\alpha, R X R \alpha, H N F 4 \alpha, L R H-1$, and SHP, was also down-regulated. A cholic acid-supplemented diet exacerbated the liver damage in Tmem30a LKO mice. TMEM30A deficiency led to intrahepatic cholestasis in mice by impairing the expression and localization of BS transporters and the expression of related nuclear receptors. Therefore, TMEM30A may be a novel genetic determinant of intrahepatic cholestasis. (Am J Pathol 2017, 187: 2775-2787; https://doi.org/10.1016/j.ajpath.2017.08.011)
\end{abstract}

Bile acids are synthesized in the liver and secreted into the gut, and they have multiple physiological functions, including bile flow, absorption of lipophilic nutrients, clearing toxic molecules, and antimicrobial and metabolic effects. ${ }^{1}$ Disturbances in bile acid homeostasis contribute to cholestasis, gallstone disease, and malabsorption. Cholestasis causes liver damage due to the excessive accumulation of bile salts (BSs) and other toxins in the liver. Hereditary mutations in hepatobiliary transporter genes result in defects in the expression and function of the

\footnotetext{
Supported by the National Basic Research Program of China grants 2016YFA0100600 and 2017YFA0103302 (Z.J.); the National Natural Science Foundation of China grants 81420108017 and 81525010 (Z.J.); the National Natural Science Foundation of China grant 81300264 (Ling.Z.); the National Key Basic Research Program of China grant 2015CB554100 (Xi.Z.); National Natural Science Foundation of China grants 81470668 and 21561142003 (Xi.Z.); the Department of Science and Technology of Sichuan Province grants 2016TD0009, 2017TJPT0010, and 2014JQ0023 (Xi.Z.); and the China Postdoctoral Science Foundation grant 2016M600734 (Lin Z.).

L.L. and Ling.Z. contributed equally to this work.

Disclosures: None declared.
} 
hepatobiliary transport systems, which are implicated in the pathogenesis of cholestasis. Progressive familial intrahepatic cholestasis (PFIC) types 1 and 2 are caused by different mutations in $A T P 8 B 1$ and $A B C B 11$ (which encodes the BS export pump, BSEP), respectively. ${ }^{2,3}$ The third type of PFIC (PFIC3) is caused by a genetic defect in $A B C B 4$ (which encodes multidrug resistance 3 ). ${ }^{4}$ Patients with PFIC often have symptoms in the neonatal period or the first year of life, and their condition usually leads to death from liver failure at ages ranging from infancy to adolescence. ${ }^{5}$ In addition, mutations in MRP2 (multidrug resistanceassociated protein 2) are associated with Dubin-Johnson syndrome, which results in jaundice and intrahepatic cholestasis of pregnancy. ${ }^{6,7}$ Recently, mutations in TJP2 (tight junction protein 2) and NIRH4 (which encodes the farnesoid X receptor, FXR) were also reported to cause progressive familial intrahepatic cholestasis in humans. ${ }^{8,9}$

ATP8B1 is a widely expressed P4-type ATPase that functions as a phospholipid flippase to maintain phospholipid asymmetry in the membrane. Compared with patients with PFIC1, Atp $8 b 1^{G 308 V / G 308 V}$ mice showed mild abnormalities, including decreased weight at weaning and elevated serum bile acid levels. ${ }^{10}$ In addition, mice deficient in ATP11C (which encodes a paralogous P4-type ATPase) exhibited impaired localization of BS transporters and plasma conjugated hyperbilirubinemia and unconjugated hypercholanemia. ${ }^{11-15}$ From these studies, the P4-ATPases have important roles in preventing intrahepatic cholestasis. Transmembrane protein 30 (TMEM30) or cell division cycle protein 50 (CDC50) binds to the P4-ATPases to form a heterodimer, and mammals express three members of the TMEM30 family: TMEM30A (CDC50A), TMEM30B (CDC50B), and TMEM30C (CDC50C). TMEM30A is ubiquitously expressed and binds 11 of 14 P4ATPases. ${ }^{16-20}$ TMEM30A is required for the flippase activity and localization of these P4-ATPases. Depletion of TMEM30A in cell lines impaired the endoplasmic reticulum (ER) exit of these P4-ATPases and caused a severe defect in the formation of membrane ruffles because of defects in the inward translocation of phosphatidylethanolamine and phosphatidylserine that subsequently inhibited cell migration. ${ }^{16-18,21}$ TMEM30A-deficient cells are engulfed by macrophages because of the exposure of phosphatidylserine in the outer leaflet in the plasma membrane, and these cells lost their ability to induce tumor formation in nude mice. ${ }^{22}$ TMEM30A also plays a key role in the uptake of the anticancer drugs and choline phospholipids in mammalian cells. ${ }^{23,24}$ Knockdown of Tmem30a in wildtype FVB mice resulted in elevated plasma levels of unconjugated BSs but no liver damage. ${ }^{13}$ However, it is still unclear whether TMEM30A plays a role in cholestasis.

In this study, we investigated the in vivo roles of Temem30a in the liver by generating Tmem30a liverspecific knockout (LKO) mice. Heterozygous Tmem30a KO first mice were crossed with Flp mice to generate Tmem $30 a^{f l o x /+}$ mice, which were then crossed with Alb-Cre mice to generate Tmem $30 a^{\text {floxfflox}}$-Alb-Cre mice. These Tmem30a LKO mice were used to investigate the function of TMEM30A in cholestasis. Tmem30a LKO mice exhibited severe hyperbilirubinemia and hypercholanemia, inflammatory infiltration, ductular proliferation, and liver fibrosis. These pathologic phenotypes in Tmem30a LKO mice were exacerbated on $0.5 \%$ cholic acid (CA)-supplemented diet. Mechanistically, the expression and localization of ATP8B1, ATP11C, and several BS transporters, including basolateral uptake transporters [organic aniontransporting polypeptide 1A4 (OATP1A4), OATP1B2, and $\mathrm{Na}^{+}$-taurocholate cotransporting polypeptide (NTCP)] and canalicular efflux transporters (BSEP and MRP2) in hepatocytes, were severely impaired. In addition, the expression of regulatory nuclear receptors related to bile acid synthesis and transport, including $\mathrm{FXR} \alpha$, retinoid $\mathrm{X}$ receptor $\alpha(\mathrm{RXR} \alpha)$, hepatocyte nuclear factor $4 \alpha(\mathrm{HNF} 4 \alpha)$, liver receptor homolog-1 (LRH-1), and short heterodimer partner (SHP), was also significantly decreased. These data demonstrated that TMEM30A is essential for the expression and proper localization of BS transporters and thereby is critical for the maintenance of BS homeostasis.

\section{Materials and Methods}

\section{Generation of Tmem30a LKO Mice}

The original Tmem $30 a$ allele is of type KO first by using the FRT-Flp strategy and also is conditional potential by using the Flox-cre system. Mice carrying the two floxed alleles on the third exon of the Tmem30a gene were generated by conventional homologous recombination in embryonic stem cells and blastocyst injection of correctly targeted embryonic stem cell clones. Tmem30a KO first mice were first interbred with Flp mice ${ }^{25}$ (The Jackson Laboratory, Bar Harbor, ME; strain name: B6.129S4-Gt(ROSA)26Sortm1(FLP1)Dym/ RainJ; stock number 009086; alias ROSA26::FLPe knock in) to generate Tmem $30 a^{f l o x /+}$ mice. Tmem $30 a^{f l o x /+}$ mice were then crossed with Albumin-Cre ${ }^{26}$ (alias Alb-Cre; The Jackson Laboratory) mice to generate LKO mice with the genotype Tmem 30a $a^{\text {flox } f \text { flox }}$-Alb-Cre mice (Supplemental Figure S1A). Tmem $30 a^{\text {floxfflox }}$ or Alb-Cre mice were used as littermate WT controls (genetic background: C57BL/6J). To monitor the efficiency of Cre-mediated deletion of the LoxP-flanked exon 3 in the liver, a TdTomato reporter ${ }^{27}$ was used [strain name: B6.Cg-Gt(ROSA)26Sortm14(CAG-TdTomato)Hze/J; alias Ai14D]. This reporter line contains a loxP-flanked STOP cassette that prevents transcription of the downstream CAG promoter-driven red fluorescent protein variant TdTomato. In the presence of Alb-Cre recombinase, the STOP cassette in the reporter mice will be removed in the Cre-expressing hepatocyte and TdTomato will be expressed. Because this CAG promoter-driven reporter construct was inserted into the Gt(ROSA)26Sor locus, TdTomato expression pattern was determined by the tissue(s) that expressed Cre recombinase. 
All animals received humane care according to the criteria outlined in the NIH's Guide for the Care and Use of Laboratory Animals, ${ }^{28}$ and all animal experiments were approved by the Animal Care and Ethics Committee at Hangzhou Normal University and Sichuan Provincial People's Hospital.

\section{Plasma Biochemistry, BS Species Identification and Quantification, and Bile Formation Assays}

Reagents for serum biochemical analysis were purchased from DiaSys Diagnostic Systems GmbH (Holzheim, Germany). All samples were tested on a Hitachi (Tokyo, Japan) Clinical Analyzer 7180, according to the manufacturer's protocols. BS species were identified and quantified as previously described in detail. ${ }^{29}$ The bile formation assays were performed as previously described in detail ${ }^{13}$; the concentration of phospholipid was tested according to the instruction (catalog number MAK122; Sigma-Aldrich, St. Louis, MO).

\section{Real-Time Quantitative PCR}

Total RNA was isolated from liver samples using Trizol (Invitrogen, Carlsbad, CA) and then reverse-transcribed and analyzed by real-time quantitative PCR with SsoFast EvaGreen Supermix (Bio-Rad, Hercules, CA) and specific primers (Table 1) on a Bio-Rad CFX96 Touch.
Liver Histologic, Immunohistochemistry, Immunofluorescence, and Western Blot Analysis

Liver tissues were fixed in $0.01 \mathrm{~mol} / \mathrm{L}$ phosphate-buffered saline (PBS; pH 7.4) containing $10 \%$ formalin and then embedded in paraffin, sectioned, and stained with hematoxylin and eosin (H\&E) and Masson blue for histologic examinations. Immunohistochemistry was performed with rabbit anti-F4/80 and cytokeratin-19 antibodies. H\&E and immunohistochemistry slices were scanned and captured with a Pannoramic MIDI (3DHISTECH Ltd., Budapest, Hungary). For immunofluorescence, frozen tissue sections were fixed in 4\% formaldehyde. After washing the samples twice with PBS, they were incubated in PBS/fetal bovine

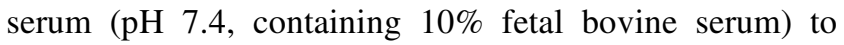
block nonspecific sites of antibody absorption. Then, these slices were incubated with appropriate primary and secondary antibodies in $0.1 \%$ saponin. The images were captured on a laser scanning confocal microscope (Carl Zeiss, Jena, Germany). The plasma membrane proteins were extracted according to the manufacturer's protocol (catalog number 71772; NovaGen, Los Angeles, CA). Liver samples $(50 \mathrm{mg})$ were homogenized in $1 \mathrm{~mL}$ of radioimmunoprecipitation lysis buffer (Beyotime, Shanghai, China) containing a protease inhibitor cocktail (Roche, Mannheim, Germany). The VersaDoc Imaging System (Bio-Rad) was used to visualize the proteins and to

Table 1 Sequences of Oligonucleotides Used in This Study

\begin{tabular}{|c|c|c|}
\hline Gene & Forward primer & Reverse primer \\
\hline Asbt & 5'-GGAACTGGCTCCAATATCCTG-3' & $5^{\prime}-$ TCCAATCACAGCTATGAGCAC- $3^{\prime}$ \\
\hline Bsep & $5^{\prime}$-ACTAATGTTGGGATCCAGGGC-3' & 5'-GGCTTTGTCCAGAGCAAGCTG-3' \\
\hline Cур7a1 & 5'-CAATGAAAGCAGCCTCTGAAG-3' & 5'-AGCCTCCTTGATGATGCTATC-3' \\
\hline Cyp27a1 & $5^{\prime}$-CCACAAGGGCCTCACCTATG-3' & $5^{\prime}$-GCACCTGGTCCAGCCGGGTG-3' \\
\hline Fgf15 & 5'-CCAACTGCTTCCTCCGAАTCC-3' & $5^{\prime}-\mathrm{TACAGTCTTCCTCCGAGTAGC-3^{ \prime }}$ \\
\hline Lrh1 & $5^{\prime}-\mathrm{AACCTCCTGAGTCTCGCACAG-} 3^{\prime}$ & $5^{\prime}$-АССTGCTCTTGGACACCTTCC-3' \\
\hline$L x r \alpha$ & $5^{\prime}-$ AATGCCAGGAGTGTCGACTT- $3^{\prime}$ & 5'-CTTGCCGCTTCAGTTTCTTC-3' \\
\hline Mrp2 & $5^{\prime}$-AGCAGGTGTTCGTTGTGTGT-3' & $5^{\prime}-$ AGCCAAGTGCATAGGTAGAGAAT- $3^{\prime}$ \\
\hline Mrp3 & $5^{\prime}$-CCCTGCGTATGAACTTAGATC-3' & $5^{\prime}$-CTGCCTCTGGCCAACACTG-3' \\
\hline Mrp4 & 5'-GCCACATCCTCATACTCAA-3' & 5'-СTCTGCTTCCTCGTTTTCT-3' \\
\hline Oatp1a1 & 5'-CAGATAAATGGATTTGCCAG- $3^{\prime}$ & 5'-GTCAACAAATAGTTACAGAG- 3' \\
\hline Oatp1a4 & $5^{\prime}$-ATAGCTTCAGGCGCATTTAC-3' & 5'-ATAGCTTCAGGCGCATTTAC-3' \\
\hline Oatp1b2 & $5^{\prime}-\mathrm{TTCACCACAACAATGGCCTA-3^{ \prime }}$ & $5^{\prime}-\mathrm{TTTTCCCCACAGACAGGTTC-3^{ \prime }}$ \\
\hline$H n f 1 \alpha$ & $5^{\prime}$-CTGATTGAAGAGCCCACA-3' & 5'-CACTCCGCCCTATTACACT-3' \\
\hline$H n f 4 \alpha$ & $5^{\prime}-\mathrm{AGACAAAGATAAGAGGAACCAG-3^{ \prime }}$ & $5^{\prime}$-CAGAGATGGGAGAGGTGA-3' \\
\hline Mdr2 & 5'-CCССTGTATTGATGCTTTC-3' & 5'-CCTTTGATGTTGTCTGGTTT-3' \\
\hline Rar & $5^{\prime}-\mathrm{TGAGCAAGACACAATGACC}-3^{\prime}$ & 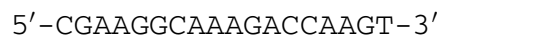 \\
\hline$R \times r$ & $5^{\prime}-\mathrm{TACGCAAAGACCTGACCTAC-3^{ \prime }}$ & 5'-СTCCACCTCGTTCTCATTC-3' \\
\hline Gr & $5^{\prime}-$ ACAGACAAGCAAGTGGAAAC - $3^{\prime}$ & $5^{\prime}$-TGAGGAGAGAAGCAGTAAGG-3' \\
\hline
\end{tabular}


quantify the band densities. All primary and secondary antibodies are listed in Table 2.

\section{Proteasome Inhibition and CA-Supplemented Diet}

For proteasome inhibition, mice were intraperitoneally injected with $0.5 \mathrm{mg} / \mathrm{kg}$ bortezomib (Selleck, Shanghai, China) or dimethyl sulfoxide and then sacrificed after 6 or 12 hours. The mice were fed a basal $14 \%$ protein diet with or without a $0.5 \%$ sodium cholate supplement (Supplemental Table S1), and the animals were weighed at 3-day intervals and monitored daily for survival. The mice were euthanized when they were experiencing severe distress, such as dramatic weight loss, back deformations, and slow movement.

\section{Statistical Analysis}

Statistical analysis was performed using one-way analysis of variance test, followed by $t$-test. A $P$ value $\leq 0.05$ was considered statistically significant.

\section{Results}

\section{Hyperbilirubinemia and Hypercholanemia in Tmem30a LKO Mice}

Tmem30a LKO mice were viable and fertile and had normal life spans. The specific depletion of TMEM30A in hepatocytes was confirmed by immunostaining and Western blot analysis with the use of specific TMEM30A antibody ${ }^{30}$ (Supplemental Figure S1, B and C), and the expression of TMEM30A in kidney and intestine was similar between littermate controls and Tmem30a LKO mice (Supplemental Figure S1D). Strong yellow pigmentation was observed in the sera from Tmem $30 a$ LKO mice compared with littermate controls at 2 months of age (Figure 1A). Serum total bile acid (TBA) levels $(168.8 \pm 66.6 \mu \mathrm{mol} / \mathrm{L} ; n=10)$ were approximately 20 -fold higher in Tmem $30 a$ LKO mice than levels in the littermate controls $(7.4 \pm 1.6 \mu \mathrm{mol} / \mathrm{L} ; n=11)$ (Figure 1B). Serum total bilirubin (TBIL) levels (20.1 \pm 6.7 $\mu \mathrm{mol} / \mathrm{L} ; n=12$ ) were approximately 15 -fold higher in Tmem30a LKO mice than levels in littermate controls $(1.4 \pm 0.2 \mu \mathrm{mol} / \mathrm{L} ; n=12)$ (Figure $1 \mathrm{C}$ ). TMEM30A deficiency primarily resulted in a dramatic increase in direct bilirubin (DBIL) levels, whereas indirect bilirubin (IBIL) levels were slightly increased (Figure 1C). Serum $\gamma$-glutamyl transferase levels were comparable between the two groups (Figure 1D). Next, TBA, TBIL, and DBIL levels were examined at various ages, and it was found that TBA $(217.2 \pm 53.1 \mu \mathrm{mol} / \mathrm{L} ; n=14)$ and TBIL $(23.7 \pm 6.3 \mu \mathrm{mol} /$ $\mathrm{L} ; n=12$ ) levels peaked at 4 months of age (Figure 1, E-G). According to the assay used to identify and quantify BS species, serum unconjugated and conjugated bile acid levels were dramatically increased (Figure 2A). Only small changes were detected in the hepatic and biliary BS species (Figure 2, B and C). Thus, hepatic TMEM30A deficiency induced intrahepatic cholestasis in mice.

Table 2 The Primary and Secondary Antibodies Used in This Study

\begin{tabular}{|c|c|c|}
\hline Name & Catalog & Manufacturer \\
\hline ATP8B1 & sc-134967 & Santa Cruz Biotechnology \\
\hline BSEP & ab112494 & Abcam, Cambridge, MA \\
\hline NTCP & ab131084 & Abcam \\
\hline LRH-1 & ab125034 & Abcam \\
\hline $\mathrm{RXR} \alpha$ & ab125001 & Abcam \\
\hline $\mathrm{F} 4 / 80$ & ab100790 & Abcam \\
\hline PKC५ & $9368 p$ & Cell Signaling Technology, Danvers, MA \\
\hline 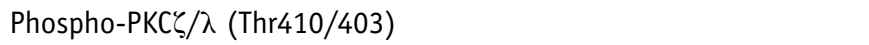 & $9378 p$ & Cell Signaling Technology \\
\hline CK-19 & $12434 \mathrm{~s}$ & Cell Signaling Technology \\
\hline Donkey anti-goat $\operatorname{IgG}(\mathrm{H}+\mathrm{L})$ secondary antibody, Alexa Fluor 546 & A11056 & Thermo Fisher Scientific \\
\hline Donkey anti-goat IgG $(\mathrm{H}+\mathrm{L})$ secondary antibody, Alexa Fluor 546 & A11010 & Thermo Fisher Scientific \\
\hline Goat anti-mouse IgG $(\mathrm{H}+\mathrm{L})$ secondary antibody, Alexa Fluor 488 & A11001 & Thermo Fisher Scientific \\
\hline Rabbit anti-mouse IgG $(\mathrm{H}+\mathrm{L})$ secondary antibody, Alexa Fluor 594 & A21205 & Thermo Fisher Scientific \\
\hline Donkey anti-rabbit $\operatorname{IgG}(\mathrm{H}+\mathrm{L})$ secondary antibody, Alexa Fluor 488 & A21206 & Thermo Fisher Scientific \\
\hline
\end{tabular}

BSEP, bile salt export pump; CK, cytokeratin; FXR, farnesoid $X$ receptor; HNF, hepatocyte nuclear factor; HRP, horseradish peroxidase; LRH, liver receptor homolog; NTCP, $\mathrm{Na}^{+}$-taurocholate cotransporting polypeptide; OATP, organic anion transporting polypeptide; PKC, protein kinase $\mathrm{C}$; RXR, retinoid X receptor; SHR, short heterodimer partner. 
A

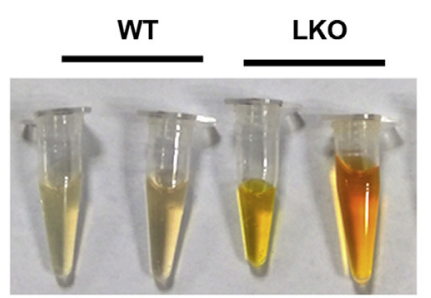

E

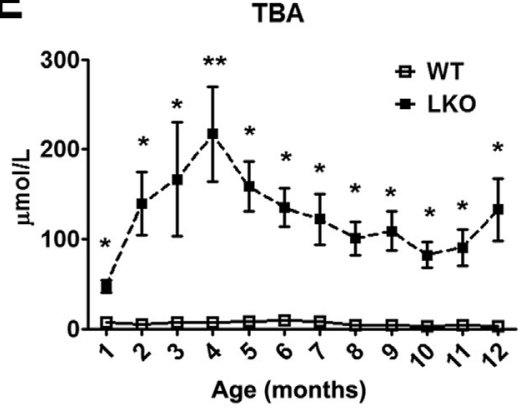

B TBA

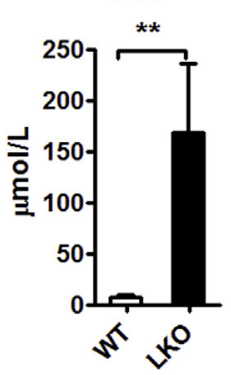

C

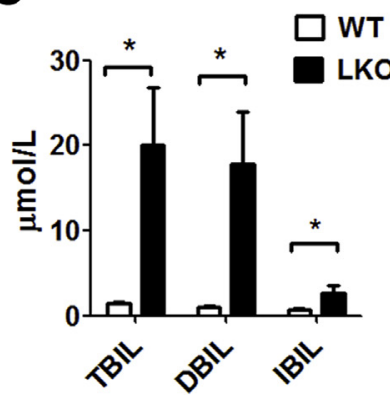

D

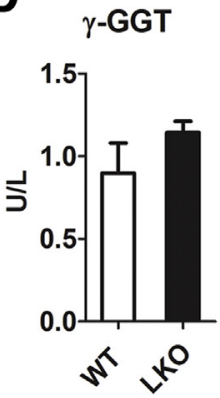

F
TBIL

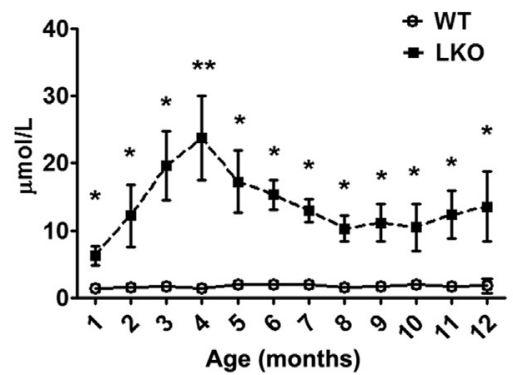

G
DBIL

Figure 1 Hyperbilirubinemia and hypercholanemia in Tmem30a liver-specific knockout (LKO) mice. A: Tmem30a LKO mice showed strong yellow pigmentation in their sera. B: Serum total bile acid (TBA) levels were dramatically elevated in Tmem30a LKO mice compared with the littermate controls. C: Serum total bilirubin (TBIL), direct bilirubin (DBIL), and indirect bilirubin (IBIL) levels were dramatically increased in Tmem30a LK0 mice compared with their littermate controls. D: Serum $\gamma$-glutamyl transferase (GGT) levels were comparable between the two groups. E-G: Serum TBA $(217.2 \pm 53.1 \mu \mathrm{mol} / \mathrm{L})(\mathbf{E})$, DBIL $(18.7 \pm 5.5 \mu \mathrm{mol} / \mathrm{L})(\mathbf{F})$, and TBIL $(23.7 \pm 6.3 \mu \mathrm{mol} / \mathrm{L})(\mathbf{G})$ levels peaked at 4 months of age, and their increased levels decreased progressively with age in Tmem30a LKO mice. All mice were at 2 months of age except for special indication. Data are expressed as means \pm SEM. $n=10$ Tmem30a LKO mice (B); $n=11$ littermate control mice (B and $\mathbf{C}) ; n=12$ Tmem30a LKO mice (C); $n=6$ to 8 mice in both groups (D); $n=14$ TBA samples (E); $n=13$ samples (F), $n=12$ samples $(\mathbf{G}) .{ }^{*} P<0.05,{ }^{*} P<0.01$ versus WT ( $t$-test). WT, wild-type.

\section{TMEM30A Deficiency Induces Liver Damage and Impairs Liver Function}

Next, the liver histologic findings and serum biochemistry variables were examined because intrahepatic cholestasis often induces liver damage and impairs liver function. Liver-to-body weight ratios of Tmem30a LKO mice were comparable with the littermate controls (Supplemental
Figure S2A). H\&E staining and the F4/80 immunohistochemistry analysis revealed significant lymphocyte and macrophage infiltration in Tmem30a-deficient livers (Supplemental Figure S2, B and C). Serum levels of inflammatory cytokines, such as IL-6, IL-18, IL-10, interferon- $\gamma$, and tumor necrosis factor- $\alpha$ were consistently increased in Tmem30a LKO mice (Supplemental Figure S2D). Masson blue staining showed that Tmem30a
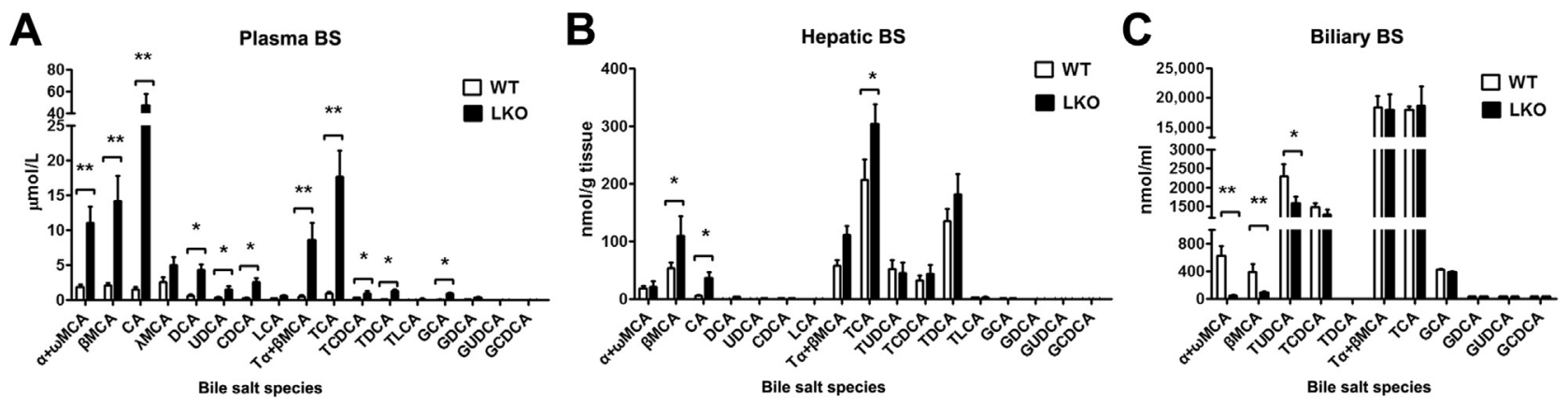

Figure 2 Identification and quantification of bile salt (BS) species in wild-type (WT) and Tmem30a liver-specific knockout (LKO) mice. A: The plasma levels of unconjugated (MCA, CA, DCA, UDCA, CDCA) and conjugated (TMCA, TCA, TCDCA, TDCA, TLCA, GCA) BS species were significantly increased in Tmem30a LKO mice. B: The levels of MCA, cholic acid (CA), and TCA in Tmem30a-deficient livers were slightly increased. C: The levels of muricholate (MCA) and TUDCA in bile were slightly changed in Tmem30a LKO mice. All samples were from mice aged 2 to 3 months. Plasma levels are expressed in $\mu \mathrm{mol} / \mathrm{L}, \mathrm{biliary}$ levels in $\mathrm{nmol} / \mathrm{mL}$, hepatic levels in $\mathrm{nmol} / \mathrm{g}$ liver, respectively. Error bars represent SEM. $n \geq 6$ mice per group $(\mathbf{A}-\mathbf{C}) .{ }^{*} P<0.05,{ }^{* *} P<0.01$ ( $t$-test). CDCA, chenodeoxycholate; DCA, deoxycholate; G, glycol; LCA, lithocholic acid; T, tauro; UDCA, ursodeoxycholate. 
LKO mice exhibited liver fibrosis, which was further confirmed by the increased levels of collagen type $1 \propto 1$ chain (Col1a1), Col3a1, and transforming growth factor- $\beta$ mRNAs (Supplemental Figure S2E). Immunohistochemistry and real-time PCR of cytokeratin-19 indicated significantly ductular proliferation in Tmem30a LKO mice (Supplemental Figure S2F). Plasma alanine aminotransferase (ALT), aspartate aminotransferase (AST), and alkaline phosphatase (ALP) levels were elevated in Tmem30a LKO mice at various ages (Supplemental Figure S3, A-C). However, serum total protein and albumin were slightly reduced (Supplemental Figure S3, D and E). Thus, hepatic deletion of TMEM30A resulted in inflammatory infiltration, ductular proliferation, and liver fibrosis.

\section{Decreased Expression of ATP11C, ATP8B1, BS Transporters, and Nuclear Receptors in Tmem30a LKO Mice}

Because TMEM30A is required for the localization and functions of P4-ATPases, the expression and localization of ATP11C and ATP8B1 were examined in Tmem30a deficient livers. Although the mRNA levels of ATP8B1 and ATP11C were not changed (Figure 3A), their protein levels were reduced in Tmem30a-deficient livers (Figure 3B). Considering that the protein levels of BS uptake transporters OATPs and NTCP are decreased in Atp11c-deficient mice, ${ }^{12,13}$ the expression of BS transporters was analyzed in Tmem30a-deficient livers. The mRNA levels of OATP1B2, NTCP, and BSEP were significantly reduced in Tmem30a-deficient livers (Figure 3A). The protein levels of
BS uptake transporters (OATP1A4, OATP1B2, and NTCP) and canalicular efflux proteins (BSEP and MRP2) were significantly reduced in Tmem30a-deficient livers (Figure 3B). These results suggested that the reduced expression of BS transporters was partially mediated by a defect in transcriptional regulation.

The expression of BS transporters and synthetic enzymes is transcriptionally regulated by hepatic nuclear receptors. Realtime PCR analysis demonstrated that the mRNA levels of nuclear receptors, including Fxr $\alpha$, Shp, Hnf $4 \alpha$, Lrh-1, Rxr $\alpha$, liver $\mathrm{X}$ receptor $\alpha$, constitutive androstane receptor, pregnane $\mathrm{X}$ receptor, and the enzymes cytochrome $\mathrm{P} 450$ family 8 subfamily B member 1 and cytochrome P450 family 27 subfamily A member 1 were decreased (Figure 3A). Moreover, the protein levels of FXR $\alpha, \mathrm{RXR} \alpha, \mathrm{LRH}-1, \mathrm{HNF} 4 \alpha$, and SHP were also significantly reduced in Tmem30a-deficient livers (Figure 3C). ATP8B1 has been shown to regulate the FXR $\alpha$ pathway by down-regulating the phosphorylation of protein kinase C (PKC) $\zeta .{ }^{31-35}$ Consistent with this result, it was observed that a significant reduction occurred in the levels of phosphorylated PKC $\zeta$ in Tmem30a-deficient livers (Figure 3D). From these findings, the decreased expression of ATP11C, ATP8B1, BS transporters, and hepatic nuclear receptors may be responsible for hyperbilirubinemia and hypercholanemia in Tmem30a LKO mice.

\section{Mislocalization of ATP11C, ATP8B1, and BS Transporters in Tmem30a LKO Mice}

The proper membrane localization of ATP8B1, ATP11C, and BS transporters is important for their functions. The
A

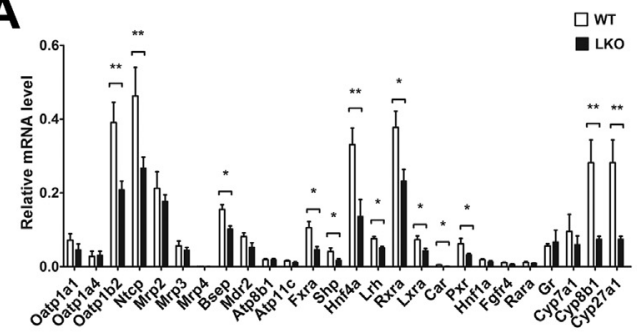

B

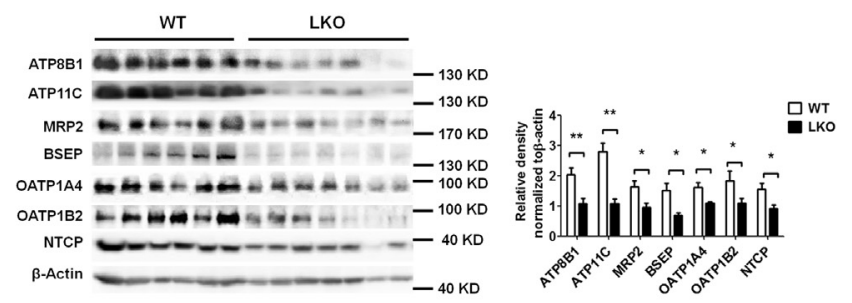

D

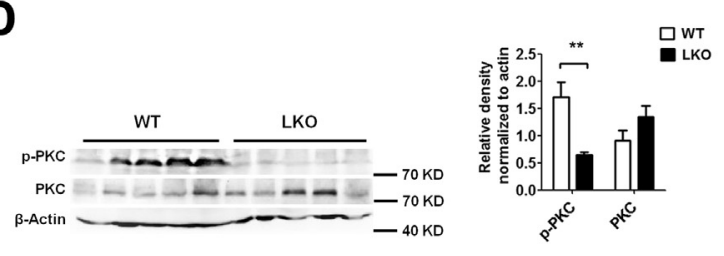

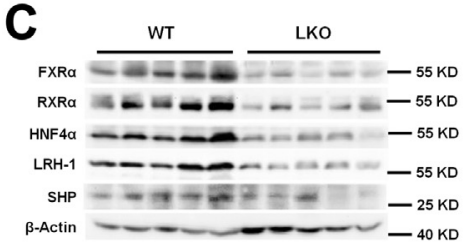

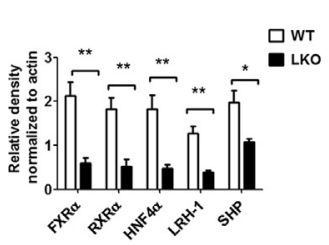

Figure 3 Analysis of mRNA and protein levels of ATP8B1, ATP11C, bile salt (BS) transporters and related nuclear receptors. A: Mean relative mRNA levels of BS transporters (0atp1b2, Ntcp, Bsep), Atp8b1, Atp11c, related nuclear receptors (Fxr $\alpha$, Shp, Hnf4 $\alpha$, Lrh, Rxr $\alpha$, Lxr $\alpha$, Car, Pxr), and enzymes (Cyp8b1, Cyp27a1) in livers were reduced in Tmem30a LK0 mice compared to the littermate controls (relative mRNA levels were normalized to $\beta$-actin). B: The protein levels of ATP8B1, ATP11C, and BS transporters in Tmem30a-deficient livers were significantly reduced compared with the littermate controls. C: The protein levels of related nuclear receptors (FXR $\alpha, \mathrm{RXR} \alpha, \mathrm{HNF} 4 \alpha, \mathrm{LRH}-1, \mathrm{SHP}$ ) were also significantly reduced in Tmem30a-deficient livers. D: Phosphorylation of protein kinase C (PKC) $\zeta$ was also dramatically reduced in Tmem30a liver-specific knockout (LKO) mice. All samples were from mice aged 2 to 3 months. Protein levels were quantified by densitometry and normalized to $\beta$-actin. Error bars represent SEM. $n \geq 4$ samples (A); $n=5$ WT and LKO (B and C); $n \geq 4$ samples per group (D). ${ }^{*} P<0.05,{ }^{*} P<0.01$ (t-test). BSEP, bile salt export pump; FXR, farnesoid $\mathrm{X}$ receptor; HNF, hepatocyte nuclear factor; LRH, liver receptor homolog; MRP, multidrug resistance-associated protein; NTCP, $\mathrm{Na}^{+}$-taurocholate cotransporting polypeptide; OATP, organic anion transporting polypeptide; RXR, retinoid $X$ receptor; SHP, small heterodimer partner; WT, wild-type. 


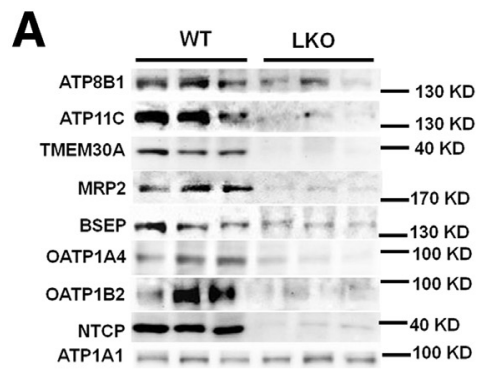

B

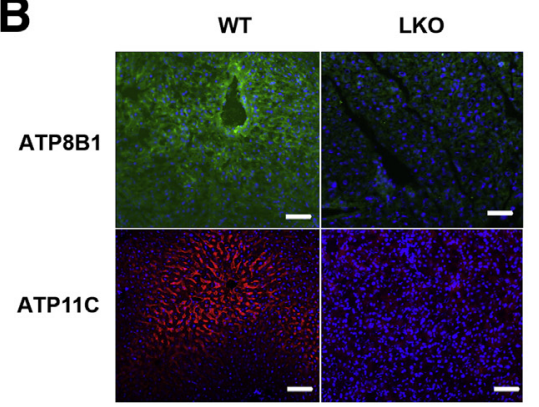

D

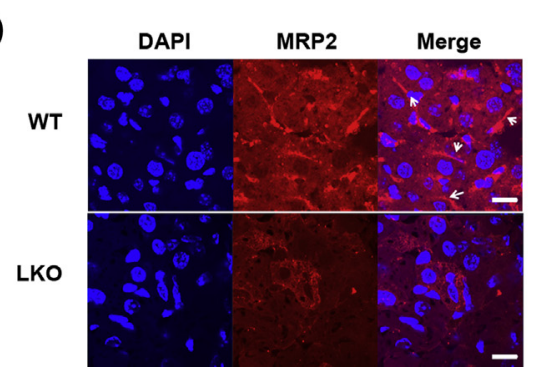

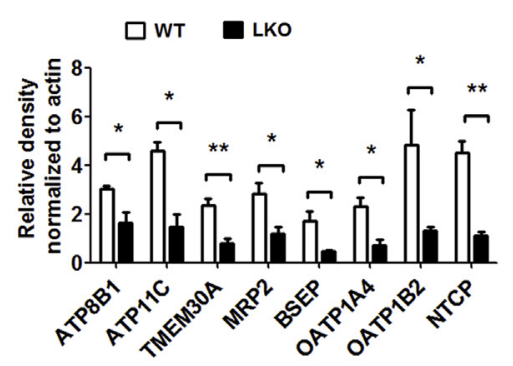

C

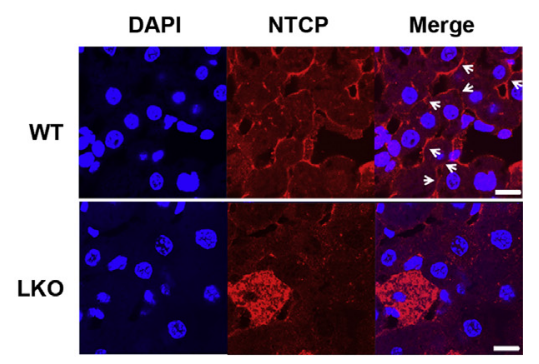

E

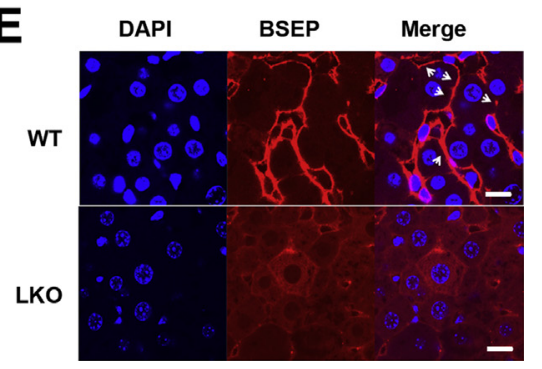

Figure 4 The localization of ATP8B1, ATP11C, and bile salt (BS) transporters was altered in the Tmem30a liver-specific knockout (LKO) mice. A: Western blot analysis of membrane proteins extracted from the livers of the Tmem30a-deficient mice and littermate controls. B: Immunofluorescence images showing the reduced expression and localization of ATP8B1 and ATP11C in Tmem30adeficient livers. C-E: Confocal images demonstrated that $\mathrm{Na}^{+}$-taurocholate cotransport protein (NTCP) (C), multidrug resistance-associated protein (MRP)2 (D), and BS export pump (BSEP) (E) in Tmem30a LKO mice were mainly localized intracellularly but not on the membrane compared with the littermate controls. White arrows indicate the membrane localization of NTCP, MRP2, and BSEP. All samples were from mice aged 2 to 3 months. Green: ATP8B1 antibody; red: primary antibodies as indicated; blue: DAPI. $n \geq 3$ samples per group (C-E). ${ }^{*} P<0.05,{ }^{* *} P<0.01$ ( $t$-test). Scale bars: $100 \mu \mathrm{m}(\mathbf{B}-\mathbf{E})$. OATP, organic anion-transporting polypeptide; WT, wild-type. membrane proteins were extracted from the livers, and Western blot analysis showed a dramatic reduction in the levels of ATP8B1, ATP11C, OATP1A4, OATP1B2, NTCP, BSEP, and MRP2 in Tmem30a-deficient livers (Figure 4A). Immunofluorescence images confirmed that the localization of these proteins was also significantly reduced on the membrane in Tmem30a-deficient hepatocytes (Figure 4B and Supplemental Figure S4). Confocal images demonstrated that the localization of NTCP, BSEP, and MRP2 was mainly intracellular but not on the membrane (Figure 4, C-E). Interestingly, TMEM30A deficiency resulted in a significant reduction of NTCP levels in both portal and central hepatocyte membrane (Supplemental Figure S4), whereas Atpllc-deficient mice show only a reduction of NTCP levels in the central area. ${ }^{13}$ It is plausible that loss of TMEM30A impaired the localization of ATP8B1, ATP11C, and BS transporters in hepatocytes.

From the reduced levels of BSEP and MRP2, it was speculated that bile formation was defective in Tmem30a LKO mice. During BS depletion, the biliary outputs of BSs, cholesterol, and phospholipids were comparable between the two groups (Figure 5, A-C). On infusion of taurocholate, the biliary outputs of BSs, cholesterol, and phospholipids were decreased in Tmem30a LKO mice (Figure 5, A-C). The biliary outputs of glutathione and ALP were reduced during bile depletion and taurocholate infusion in Tmem30a LKO mice (Figure 5, D and E). Thus, Tmem30a LKO mice exhibited defects in bile formation.

\section{Normal Intestinal BS-Related Proteins and Other Organ Function}

Enterohepatic circulation is also important in BS homeostasis. After being released in the gut, BSs are mainly reabsorbed in the terminal ileum by apical sodiumdependent BS transporters (ASBT) and other related proteins. Tmem30a deficiency did not affect the mRNA levels of Abst, fibroblast growth factor-15, Fxr $\alpha$, and Shp in the intestine (Supplemental Figure S5A), and the protein levels of ABST, ATP8B1, and FXR $\alpha$ were also no different between the two groups (Supplemental Figure S5B). The plasma creatinine, blood urea nitrogen, and uric acid levels in Tmem30a LKO mice were comparable with the littermate controls at various ages (Supplemental Figure S5, C-E). $\mathrm{H} \& \mathrm{E}$ staining of heart, kidney, lung, spleen, muscle, pancreas, and intestine showed no significant differences at 12 months of age between littermate controls and Tmem30a LKO mice (Supplemental Figures S6-S8). Thus, the intestinal BS-related proteins and functions of other organs were not affected in Tmem30a LKO mice. 

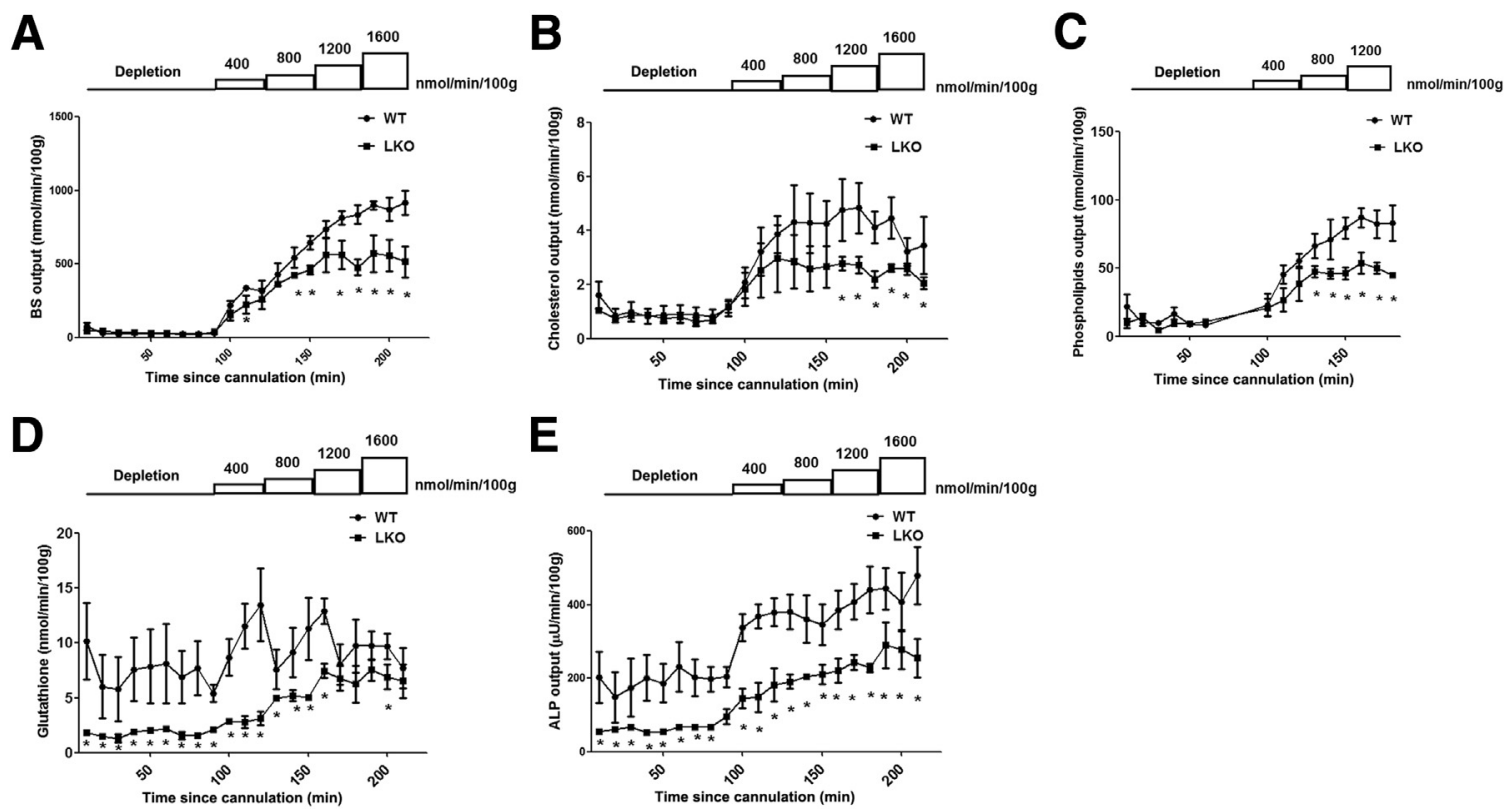

Figure 5 Bile formation was impaired in Tmem30a liver-specific knockout (LK0) mice. The endogenous bile salt (BS) pools were depleted from Tmem30a LKO mice and littermate controls for 90 minutes. Taurocholate (TC) was infused through the jugular vein, and the infusion rates increased in a stepwise manner every 30 minutes at $400 \mathrm{nmol} /$ min per $100 \mathrm{~g}$ for each step $(400,800,1200,1600 \mathrm{nmol} / \mathrm{min}$ per $100 \mathrm{~g})$. A-C: No difference was found in the biliary outputs of BS (A), cholesterol (B), and phospholipids (C) between Tmem30a LKO mice and littermate controls during BS depletion. However, the biliary outputs of BS, cholesterol, and phospholipids were significantly decreased in Tmem30a LKO mice with the increased infusion rates. D and E: The biliary outputs of glutathione (D) and alkaline phosphatase (ALP) (E) were significantly reduced in Tmem30a LKO mice during both bile depletion and TC infusion. All male mice were tested at 2 to 3 months age. Error bars represent SEM. $n \geq 3$ male mice per group (D and $\mathbf{E}$ ). ${ }^{*} P<0.05$ (one-way analysis of variance analysis). WT, wild-type.

\section{Enhanced Proteasomal Degradation of ATP11C, ATP8B1, and BS Transporters in Tmem30a LK0 Mice}

TMEM30A-deficient cells exhibited defects in the ER exit, ${ }^{16-18}$ and it was speculated that this deficiency may lead to the accumulation of ATP8B1, ATP11C, and BS transporters in the ER and may induce proteasomal degradation. On proteasome inhibition with bortezomib, the protein levels of ATP8B1, ATP11C, OATP1B2, NTCP, BSEP, and MRP2 were partially restored in Tmem30a LKO mice (Figure 6, A and B). However, immunofluorescence staining indicated that the membrane localization of ATP8B1, ATP11C, and BS transporters was not restored. Instead, these proteins were co-localized with protein disulfide isomerase in the ER after the bortezomib treatment, suggesting that they were accumulated in the ER (Supplemental Figure S9). Interestingly, the protein levels of FXR $\alpha, \operatorname{RXR} \alpha, \mathrm{HNF} 4 \alpha, \mathrm{LRH}-1$, and SHP were also increased in Tmem30a-deficient livers on proteasome inhibition (Figure 6, C and D). These increased nuclear receptors may partially up-regulate the mRNA levels of BS transporters compared with dimethyl sulfoxide controls in the Tmem30a LKO mice group (Supplemental Figure S10). Therefore, the reduction of BS transporters in Tmem $30 a$ LKO mice was not only attributed to the proteasomal degradation induced by the impaired trafficking of ATP8B1, ATP11C, and BS transporters but also the decreased transcriptional activation.
Exogenous Bile Acids Exacerbated the Phenotypes in Tmem30a LKO Mice

The mice were challenged with a $0.5 \%$ CA-supplemented diet to further substantiate these findings. Jaundice was only observed in Tmem30a LKO mice (Supplemental Figure S11A). The plasma levels of TBA, TBIL, DBIL, ALT, AST, and ALP were dramatically increased in Tmem30a LKO mice after 9 days on the CA-supplemented diet (Figure 7, A-C). The serum total protein and albumin levels were obviously reduced in Tmem30a LKO mice (Supplemental Figure S11B). No obvious difference was observed in serum creatinine, blood urea nitrogen, and uric acid levels (Supplemental Figure S11C). Male Tmem30a LKO mice lost weight more rapidly than the littermate controls on CA-supplemented diet for 2 weeks (Figure 7D). Moreover, more than one-half of the male Tmem30a LKO mice died within 2 weeks, whereas all male littermate controls survived (Figure 7E). Morbid Tmem30a LKO mice, which showed dramatic weight loss, back deformations, and slow movements, were sacrificed for further analysis. Liverto-body weight ratios of the morbid mice were dramatically reduced compared with the mice with normal feeding (Supplemental Figures S2A and S11D). H\&E staining showed more multinucleate hepatocytes and smaller hepatocyte sizes in morbid Tmem30a LKO mice (Figure 7F). The increased levels of Colla1, Col3a1, and transforming growth factor- $\beta$ mRNAs indicated severe liver fibrosis, and 
A
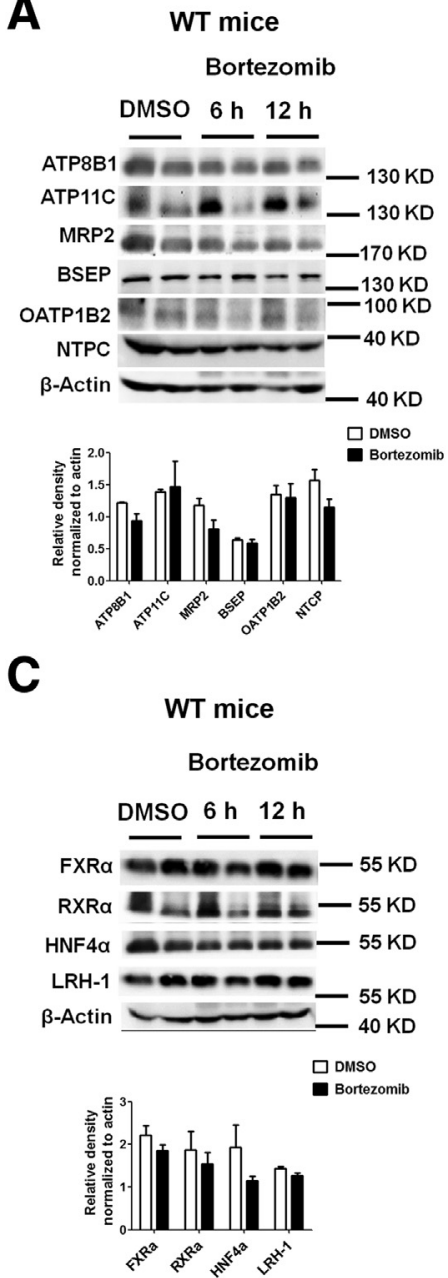

B

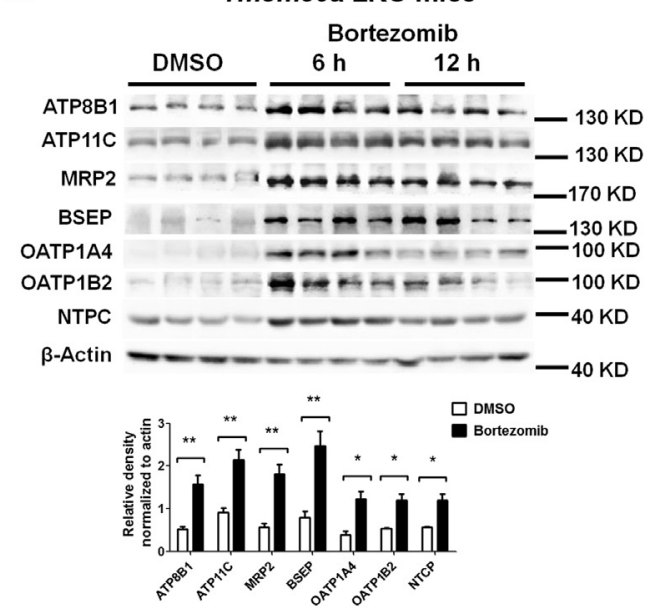

D

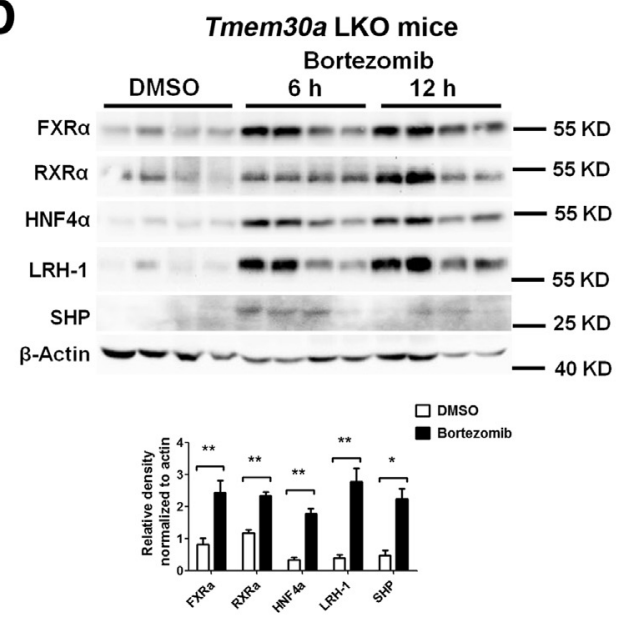

Figure 6 Protein levels of bile salt (BS) transporters and related nuclear receptors were partially restored in Tmem30a liver-specific knockout (LKO) mice after treatment with the proteasome inhibitor. All mice were sacrificed 6 and 12 hours after treatment with the proteasome inhibitor bortezomib $(0.5 \mathrm{mg} / \mathrm{kg})$. A and $\mathbf{B}$ : Compared with their dimethyl sulfoxide (DMSO) control groups, wild-type (WT) mice treated with bortezomib showed no difference in the protein levels of ATP8B1, ATP11C and BS transporters (A), whereas Tmem30a LKO mice treated with bortezomib showed dramatically increased levels of these proteins (B). C and D: Compared with their DMSO control groups, WT mice treated with bortezomib showed no difference in the protein levels of farnesoid $\mathrm{X}$ receptor (FXR) $\alpha$, retinoid $\mathrm{X}$ receptor (RXR) $\alpha$, hepatocyte nuclear factor (HNF4) $\alpha$, liver receptor homolog (LRH)-1, and small heterodimer partner (SHP) (C), whereas Tmem30a LKO mice treated with bortezomib showed dramatically increased levels of these nuclear receptors (D). All mice () were tested at 2 to 3 months age. Protein levels were quantified by densitometry and normalized to $\beta$-actin. $n \geq 3$ mice per group. ${ }^{*} P<0.05,{ }^{*} P P<0.01$ (t-test). BSEP, bile salt export pump; MRP, multidrug resistanceassociated protein; NTCP, $\mathrm{Na}^{+}$-taurocholate cotransport protein; OATP, organic anion transporting polypeptide.
Masson blue staining confirmed this result in Tmem30a LKO mice (Supplemental Figure S11, E and F). H\&E staining showed that there were no obvious differences in other organs, such as heart, kidney, brain, intestine, and spleen (Supplemental Figures S12 and S13). Interestingly, serum TBA, TBIL, and DBIL levels and serum ALT, AST, and ALP levels were also increased in surviving Tmem30a LKO mice (Supplemental Figure S14, A and B) but not as dramatically as morbid Tmem30a LKO mice (Figure 7, $\mathrm{A}-\mathrm{C}$ ). In addition, $\mathrm{H} \& \mathrm{E}$ staining did not reveal any more difference except for unclear cell boundaries in surviving Tmem30a LKO mice (Supplemental Figure S14C). In summary, the CA-supplemented diet exacerbated the phenotypes and led to more severe liver damage in Tmem30a LKO mice. However, the molecular mechanisms underlying this phenotype are not clear, and further investigation is warranted.

\section{Discussion}

As a $\beta$-subunit, TMEM30A is essential for the function of both ATP8B1 and ATP11C. ${ }^{16,20}$ Atp8b1 mutant mice exhibited mild abnormalities, and the cholestatic phenotypes were only revealed in Atp $8 b 1$ mutant mice challenged with a CA-supplemented diet. ${ }^{10,36}$ In contrast, Atpl lc-deficient mice exhibited conjugated hyperbilirubinemia and unconjugated hypercholanemia. Similar to the Atp11c-deficient mice, Tmem30a-deficient mice showed a dramatic reduction in the levels of OATP1A4 and OATP1B2, which may be responsible for the increased levels of conjugated bilirubin and unconjugated bile acid. Consistently, these phenotypes were also observed in Oatpla/1 $b^{-/-}$mice. ${ }^{37}$ Furthermore, the distribution of BS species (approximately $80 \%$ of the total plasma BS species were unconjugated) in Tmem30a LKO mice was also comparable with the distribution observed in Atpllc-deficient mice. Therefore, the two mouse models have several similar phenotypes in intrahepatic cholestasis. Nevertheless, Tmem30a-deficient mice exhibited more severe defects than Atpl1c-deficient mice, as indicated by the 15 -fold versus sixfold increase in plasma bilirubin levels as well as the 20 -fold versus 10 -fold increase in plasma total bile acid levels.

There are several explanations for the stronger phenotypes observed in Tmem30a LKO mice. First, in addition to 

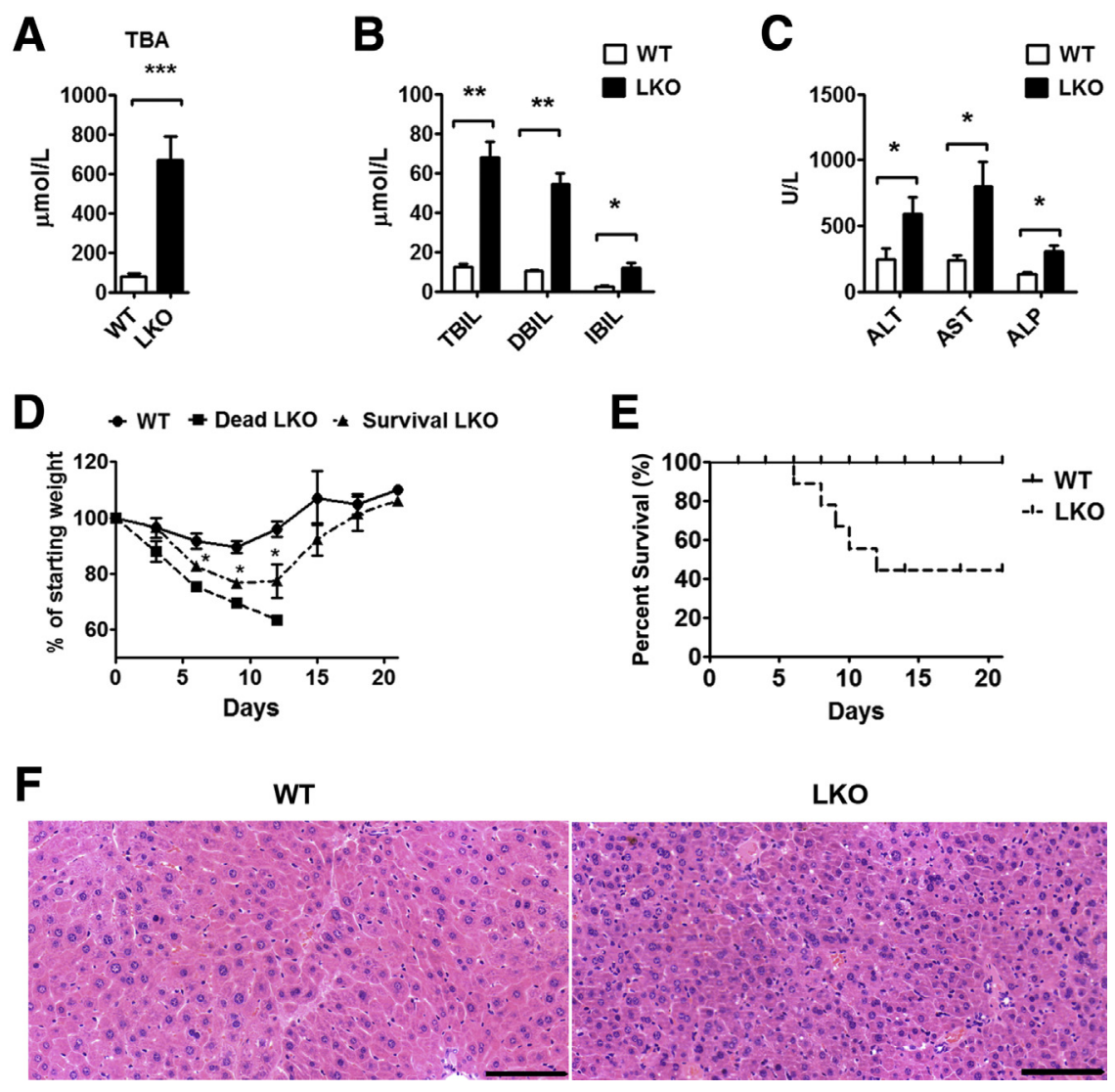

Figure 7 Exacerbation of the Tmem30a-deficient phenotypes on cholic acid (CA)-supplemented diet. Male Tmem30a-deficient mice and male littermate controls (2 to 3 months) were fed a $0.5 \%$ CA-supplemented diet. A-C: Serum total bile acid (TBA) levels (A); serum total bilirubin (TBIL), direct bilirubin (DBIL), and indirect bilirubin (IBIL) levels (B); and serum alanine aminotransferase (ALT), aspartate aminotransferase (AST), and alkaline phosphatase (ALP) levels (C) were dramatically increased in Tmem30a liver-specific knockout (LKO) mice compared with the littermate controls after 9 days on CAsupplemented diet. D: The body weight ratios of male Tmem30a LKO mice were dramatically decreased compared with male littermate controls after 3 weeks on CA-supplemented diet. The body weight ratios were normalized to the weight on day 0 (weight before receiving $C A$ ). The mice were weighed at 3-day intervals. E: Death of male Tmem30a LKO mice and male littermate controls after 3 weeks on CA-supplemented diet. Mice were monitored every day for the survival curve. F: Hematoxylin and eosin (H\&E) staining showed the presence of more multinucleate hepatocytes and smaller hepatocyte sizes in morbid male Tmem30a LKO mice but not the littermate controls on CAsupplemented diet. Error bars represent SEM. $n=15$ male Tmem30a-deficient mice; $n=10$ male littermate control mice. ${ }^{*} P<0.05$, ${ }^{* *} P<0.01,{ }^{* * *} P<0.001$ (t-test). Scale bars $=100 \mu \mathrm{m}$. Original magnification, $\times 200$. the defect in the re-uptake of conjugated bilirubin due to reduced OATP levels, ${ }^{37,38}$ Tmem30a LKO mice but not Atpllc-deficient mice showed an extra defect in the expression and localization of MRP2. MRP2 primarily secretes conjugated bilirubin into the bile, and its mutations result in Dubin-Johnson syndrome, which is characterized by conjugated hyperbilirubinemia. ${ }^{38,39}$ Therefore, the reduced MRP2 levels could explain the higher conjugated bilirubin levels in Tmem30a LKO mice. Second, the reduced expression and localization of BSEP were only observed in Tmem30a LKO mice but not in Atpllcdeficient mice, possibly explaining higher total bile acid levels in Tmem30a LKO mice. Third, the localization of NCTP in the portal and central hepatocyte membranes was reduced in Tmem 30 a LKO mice, whereas Atpllc-deficient mice only lacked NTCP in the central hepatocyte membrane. ${ }^{13}$ This outcome may contribute to the increased tauro- and glyco-conjugated BS levels in Tmem30a LKO mice. Finally, biliary outputs of cholesterol, ALP, and glutathione were consistent with BSs output, which was decreased in Tmem30a LKO mice, and unchanged in Atpllc-mutant mice, but increased in Atp $8 b 1$-deficient mice. ${ }^{13,36}$ The reduction of BA synthetic enzymes CYP8B1 and CYP27A1 might be involved in the decrease in BSs output. Both BSEP and MRP2 functions are important for bile formation ${ }^{40,41}$; therefore, the defects in bile formation in
Tmem $30 a \mathrm{KO}$ mice could be due to the reduced expression of BA synthetic enzymes and transporter proteins.

BS transporters are transcriptionally regulated by a complex interacting network of nuclear receptors. ${ }^{1,42,43}$ In Tmem30a LKO mice, the mRNA and protein levels of these nuclear receptors, including FXR $\alpha$, were markedly reduced. $\mathrm{FXR} \alpha$ is a critical nuclear receptor for bile acids and regulates the expression of basolateral BS uptake and canalicular efflux transporters, including NTCP, OATPs, BSEP, and MRP2. In addition, $\mathrm{FXR} \alpha$ also regulates the activity and/or expression of other nuclear receptors, which subsequently regulate the expression of BS transporters. ${ }^{1,42,43}$ On proteasome inhibition with bortezomib, the protein levels of hepatic nuclear receptors and BS transporters were partially restored in Tmem 30 a LKO mice, indicating that the reduction of these proteins was mediated by proteasomal degradation. The mRNA levels of BS transporters were also partially restored, suggesting that the reduced hepatic nuclear receptors were partly responsible for the decreased expression of BS transporters. Nevertheless, serum elevated BSs could also influence the expression of nuclear receptors, BS transporters and synthetic enzymes as a compensatory mechanism. Mutations in ATP8B1 have been suggested to suppress the expression and activity of FXR $\alpha$ by decreasing PKC phosphorylation. ${ }^{31-35,44}$ Consistent with this finding, Tmem30a-deficient livers exhibited a marked decrease in the 
levels of phosphorylated PKC. Thus, the impaired expression and localization of ATP8B1 may be responsible for the decreased activity of the FXR $\alpha$ pathway in Tmem30a-deficient livers. Taken together, the reduced expression of BS transporters was not only attributed to the proteasomal degradation but also to the reduced expression of the nuclear receptors.

TMEM30A deficiency impaired the ER exit and catalytic phospholipid flippase activity of the P4 ATPase, which maintains an asymmetric distribution of phospholipids on the membrane to ensure membrane fluidity and constitutive signal transduction. ${ }^{16,21,45}$ In addition, the phospholipid flippase complex serves as a molecular scaffold to recruit signaling molecules and to provide a docking platform for proteins of the vesicle-generating machinery. ${ }^{13,21}$ It is plausible that Tmem30a deficiency blocked vesicle assembly and led to the accumulation of cargo proteins. Consequently, cargo proteins, including OATPs, NTCP, MRP2, BSEP, ATP8B1, and ATP11C, were targeted for proteasomal degradation. In line with this, proteasome inhibition by bortezomib led to a partial restoration of the levels of ATP8B1, ATP11C, and BS transporters. Confocal images demonstrated that the restored ATP8B1, ATP11C, and BS transporters were stained with protein disulfide isomerase in the ER, suggesting that the defective trafficking of vesicles containing these proteins was induced by TMEM30A deficiency. In addition, the phosphorylation of $\mathrm{PKC} \zeta$ has been implicated in the transportation of NTCP vesicles and the canalicular localization of BSEP and MRP2 $2^{46-48}$; therefore, the insufficient phosphorylation of PKC $\zeta$ in Tmem30adeficient mice might also contribute to the impaired localization of BS transporters. From these results, the impaired expression and localization of P4-ATPases induced by Tmem30a deficiency may affect the intracellular transport of vesicles containing BS transporters.

The present Tmem30a LKO mouse model displayed several interesting pathologic features that have not been reported in the previous Atp8b1- and Atp11c-deficient mice. Histologic and biochemical analyses showed dramatically increased inflammatory infiltration and liver damage, which may be attributed to more severe intrahepatic cholestasis in Tmem30a LKO mice. Another possibility is that the exposure of phosphatidylserine on the surface of Tmem30adeficient hepatocytes elicited an eat me signal for the macrophages. ${ }^{22}$ The impaired bile formation in Tmem $30 a$ deficient mice also caused the accumulation of BSs in hepatocytes, which then exacerbated the liver damage. With the CA-supplemented diet, the reduction of OATPs and NTCP could reduce the uptake of cholic acid by hepatocytes, but hydrophobic cholic acid could still enter into the hepatocytes by passive diffusion. ${ }^{49,50}$ In contrast to Atpllcdeficient mice, only $60 \%$ of Tmem30a-deficient mice died after consuming the CA-supplemented diet. It is speculated that these discrepancies may be due to the differences in gene deletion strategies. In contrast to the whole-body deletion of ATP11C, our mouse model was a LKO. Other organ and tissue in Tmem30a-deficient mice may compensate for the CA-challenge and make a few survivals. Except for intrahepatic cholestasis, Atp11c mutations in mice have been reported to cause macrophage infiltration, B-cell deficiency, dystocia, hepatocellular carcinoma, ${ }^{11,14,15,22,51}$ which could promote the deterioration of overall viability, particularly after severe challenges.

\section{Conclusions}

This study provides a clinically relevant mouse model with phenotypes of intrahepatic cholestasis. Hepatocyte-specific Tmem30a KO mice present many manifestations of human intrahepatic cholestasis. TMEM30A may be a novel genetic determinant of liver disorders characterized by hyperbilirubinemia and hypercholanemia. Mutations in ATP8B1, $B S E P$, and FXRA have been shown to cause hereditary intrahepatic cholestasis in humans, and screening for TMEM30A mutations in patients with hereditary intrahepatic cholestasis could yield interesting findings. Taken together, this study demonstrated a critical role of TMEM30A in hepatic BS homeostasis and provided new insights into the molecular mechanisms of intrahepatic cholestasis.

\section{Acknowledgments}

All authors contributed to study conception and design as well as writing the manuscript; L.L., Ling.Z., LinZ., F.Y., Xu.Z., Z.L., Y.Y., H.L., L.F., and Z.W. acquired data; L.L., Ling.Z., H.J., Z.J., and Xi.Z. analyzed and interpreted data; H.C., S.Y., and L.W. provided surgical technical support; H.J., Z.J., Xi.Z., and Ling.Z. obtained funding and supervised the study.

\section{Supplemental Data}

Supplemental material for this article can be found at https://doi.org/10.1016/j.ajpath.2017.08.011.

\section{References}

1. Halilbasic E, Claudel T, Trauner M: Bile acid transporters and regulatory nuclear receptors in the liver and beyond. J Hepatol 2013, 58: $155-168$

2. Bull LN, van Eijk MJ, Pawlikowska L, DeYoung JA, Juijn JA, Liao M, Klomp LW, Lomri N, Berger R, Scharschmidt BF, Knisely AS, Houwen RH, Freimer NB: A gene encoding a P-type ATPase mutated in two forms of hereditary cholestasis. Nat Genet 1998, 18:219-224

3. Strautnieks SS, Bull LN, Knisely AS, Kocoshis SA, Dahl N, Arnell H, Sokal E, Dahan K, Childs S, Ling V, Tanner MS, Kagalwalla AF, Nemeth A, Pawlowska J, Baker A, Mieli-Vergani G, Freimer NB, Gardiner RM, Thompson RJ: A gene encoding a liverspecific $A B C$ transporter is mutated in progressive familial intrahepatic cholestasis. Nat Genet 1998, 20:233-238 
4. Deleuze JF, Jacquemin E, Dubuisson C, Cresteil D, Dumont M, Erlinger S, Bernard O, Hadchouel M: Defect of multidrug-resistance 3 gene expression in a subtype of progressive familial intrahepatic cholestasis. Hepatology 1996, 23:904-908

5. Davit-Spraul A, Gonzales E, Baussan C, Jacquemin E: Progressive familial intrahepatic cholestasis. Orphanet J Rare Dis 2009, 4:1

6. Suzuki H, Sugiyama Y: Single nucleotide polymorphisms in multidrug resistance associated protein 2 (MRP2/ABCC2): its impact on drug disposition. Adv Drug Deliv Rev 2002, 54:1311-1331

7. Sookoian S, Castano G, Burgueno A, Gianotti TF, Pirola CJ: Association of the multidrug-resistance-associated protein gene (ABCC2) variants with intrahepatic cholestasis of pregnancy. J Hepatol 2008, $48: 125-132$

8. Sambrotta M, Strautnieks S, Papouli E, Rushton P, Clark BE, Parry DA, Logan CV, Newbury LJ, Kamath BM, Ling S, Grammatikopoulos T, Wagner BE, Magee JC, Sokol RJ, MieliVergani G; University of Washington Center for Mendelian Genomics, Smith JD, Johnson CA, McClean P, Simpson MA, Knisely AS, Bull LN, Thompson RJ: Mutations in TJP2 cause progressive cholestatic liver disease. Nat Genet 2014, 46:326-328

9. Gomez-Ospina N, Potter CJ, Xiao R, Manickam K, Kim MS, Kim KH, Shneider BL, Picarsic JL, Jacobson TA, Zhang J, He W, Liu P, Knisely AS, Finegold MJ, Muzny DM, Boerwinkle E, Lupski JR, Plon SE, Gibbs RA, Eng CM, Yang Y, Washington GC, Porteus MH, Berquist WE, Kambham N, Singh RJ, Xia F, Enns GM, Moore DD: Mutations in the nuclear bile acid receptor FXR cause progressive familial intrahepatic cholestasis. Nat Commun 2016, 7:10713

10. Pawlikowska L, Groen A, Eppens EF, Kunne C, Ottenhoff R, Looije N, Knisely AS, Killeen NP, Bull LN, Elferink RP, Freimer NB: A mouse genetic model for familial cholestasis caused by ATP8B1 mutations reveals perturbed bile salt homeostasis but no impairment in bile secretion. Hum Mol Genet 2004, 13: 881-892

11. Siggs OM, Schnabl B, Webb B, Beutler B: X-linked cholestasis in mouse due to mutations of the P4-ATPase ATP11C. Proc Natl Acad Sci U S A 2011, 108:7890-7895

12. Matsuzaka Y, Hayashi H, Kusuhara H: Impaired hepatic uptake by organic anion-transporting polypeptides is associated with hyperbilirubinemia and hypercholanemia in Atp11c mutant mice. Mol Pharmacol 2015, 88:1085-1092

13. de Waart DR, Naik J, Utsunomiya KS, Duijst S, Ho-Mok K, Bolier AR, Hiralall J, Bull LN, Bosma PJ, Oude Elferink RP, Paulusma CC: ATP11C targets basolateral bile salt transporter proteins in mouse central hepatocytes. Hepatology 2016, 64:161-174

14. Yabas M, Teh CE, Frankenreiter S, Lal D, Roots CM, Whittle B, Andrews DT, Zhang Y, Teoh NC, Sprent J, Tze LE, Kucharska EM, Kofler J, Farell GC, Broer S, Goodnow CC, Enders A: ATP11C is critical for the internalization of phosphatidylserine and differentiation of B lymphocytes. Nat Immunol 2011, 12:441-449

15. Siggs OM, Arnold CN, Huber C, Pirie E, Xia Y, Lin P, Nemazee D, Beutler B: The P4-type ATPase ATP11C is essential for B lymphopoiesis in adult bone marrow. Nat Immunol 2011, 12:434-440

16. Paulusma CC, Folmer DE, Ho-Mok KS, de Waart DR, Hilarius PM, Verhoeven AJ, Oude Elferink RP: ATP8B1 requires an accessory protein for endoplasmic reticulum exit and plasma membrane lipid flippase activity. Hepatology 2008, 47:268-278

17. Bryde S, Hennrich H, Verhulst PM, Devaux PF, Lenoir G, Holthuis JC: CDC50 proteins are critical components of the human class-1 P4-ATPase transport machinery. J Biol Chem 2010, 285: 40562-40572

18. van der Velden LM, Wichers CG, van Breevoort AE, Coleman JA, Molday RS, Berger R, Klomp LW, van de Graaf SF: Heteromeric interactions required for abundance and subcellular localization of human CDC50 proteins and class 1 P4-ATPases. J Biol Chem 2010, 285:40088-40096

19. Folmer DE, Mok KS, de Wee SW, Duijst S, Hiralall JK, Seppen J, Oude Elferink RP, Paulusma CC: Cellular localization and biochemical analysis of mammalian CDC50A, a glycosylated betasubunit for P4 ATPases. J Histochem Cytochem 2012, 60:205-218

20. Takatsu H, Baba K, Shima T, Umino H, Kato U, Umeda M, Nakayama K, Shin HW: ATP9B, a P4-ATPase (a putative aminophospholipid translocase), localizes to the trans-Golgi network in a CDC50 proteinindependent manner. J Biol Chem 2011, 286:38159-38167

21. Kato U, Inadome $\mathrm{H}$, Yamamoto $\mathrm{M}$, Emoto $\mathrm{K}$, Kobayashi $\mathrm{T}$, Umeda M: Role for phospholipid flippase complex of ATP8A1 and CDC50A proteins in cell migration. J Biol Chem 2013, 288: 4922-4934

22. Segawa K, Kurata S, Yanagihashi Y, Brummelkamp TR, Matsuda F, Nagata S: Caspase-mediated cleavage of phospholipid flippase for apoptotic phosphatidylserine exposure. Science 2014, 344:1164-1168

23. Munoz-Martinez F, Torres C, Castanys S, Gamarro F: CDC50A plays a key role in the uptake of the anticancer drug perifosine in human carcinoma cells. Biochem Pharmacol 2010, 80:793-800

24. Chen R, Brady E, McIntyre TM: Human TMEM30a promotes uptake of antitumor and bioactive choline phospholipids into mammalian cells. J Immunol 2011, 186:3215-3225

25. Farley FW, Soriano P, Steffen LS, Dymecki SM: Widespread recombinase expression using FLPeR (flipper) mice. Genesis 2000, 28:106-110

26. Postic C, Shiota M, Niswender KD, Jetton TL, Chen Y, Moates JM, Shelton KD, Lindner J, Cherrington AD, Magnuson MA: Dual roles for glucokinase in glucose homeostasis as determined by liver and pancreatic beta cell-specific gene knock-outs using Cre recombinase. J Biol Chem 1999, 274:305-315

27. Madisen L, Zwingman TA, Sunkin SM, Oh SW, Zariwala HA, Gu H, Ng LL, Palmiter RD, Hawrylycz MJ, Jones AR, Lein ES, Zeng H: A robust and high-throughput Cre reporting and characterization system for the whole mouse brain. Nat Neurosci 2010, 13:133-140

28. Committee for the Update of the Guide for the Care and Use of Laboratory Animals: National Research Council: Guide for the Care and Use of Laboratory Animals: Eighth Edition. Washington, DC, National Academies Press, 2011

29. Garcia-Canaveras JC, Donato MT, Lahoz A: Ultra-performance liquid chromatography-mass spectrometry targeted profiling of bile acids: application to serum, liver tissue, and cultured cells of different species. Methods Mol Biol 2014, 1198:233-247

30. Coleman JA, Molday RS: Critical role of the beta-subunit CDC50A in the stable expression, assembly, subcellular localization, and lipid transport activity of the P4-ATPase ATP8A2. J Biol Chem 2011, 286: 17205-17216

31. Alvarez L, Jara P, Sanchez-Sabate E, Hierro L, Larrauri J, Diaz MC, Camarena C, De la Vega A, Frauca E, Lopez-Collazo E, Lapunzina P: Reduced hepatic expression of farnesoid $\mathrm{X}$ receptor in hereditary cholestasis associated to mutation in ATP8B1. Hum Mol Genet 2004, 13:2451-2460

32. Frankenberg T, Miloh T, Chen FY, Ananthanarayanan M, Sun AQ, Balasubramaniyan N, Arias I, Setchell KD, Suchy FJ, Shneider BL: The membrane protein ATPase class I type 8B member 1 signals through protein kinase $\mathrm{C}$ zeta to activate the farnesoid $\mathrm{X}$ receptor. Hepatology 2008, 48:1896-1905

33. Chen F, Ananthanarayanan M, Emre S, Neimark E, Bull LN, Knisely AS, Strautnieks SS, Thompson RJ, Magid MS, Gordon R, Balasubramanian N, Suchy FJ, Shneider BL: Progressive familial intrahepatic cholestasis, type 1, is associated with decreased farnesoid X receptor activity. Gastroenterology 2004, 126:756-764

34. Koh S, Takada T, Kukuu I, Suzuki H: FIC1-mediated stimulation of FXR activity is decreased with PFIC1 mutations in HepG2 cells. J Gastroenterol 2009, 44:592-600

35. Chen F, Ellis E, Strom SC, Shneider BL: ATPase Class I Type 8B Member 1 and protein kinase $\mathrm{C}$ zeta induce the expression of the canalicular bile salt export pump in human hepatocytes. Pediatr Res 2010, 67:183-187

36. Paulusma CC, Groen A, Kunne C, Ho-Mok KS, Spijkerboer AL, Rudi de Waart D, Hoek FJ, Vreeling H, Hoeben KA, van Marle J, 
Pawlikowska L, Bull LN, Hofmann AF, Knisely AS, Oude Elferink RP: Atp8b1 deficiency in mice reduces resistance of the canalicular membrane to hydrophobic bile salts and impairs bile salt transport. Hepatology 2006, 44:195-204

37. van de Steeg E, Wagenaar E, van der Kruijssen CM, Burggraaff JE, de Waart DR, Elferink RP, Kenworthy KE, Schinkel AH: Organic anion transporting polypeptide $1 \mathrm{a} / 1 \mathrm{~b}$-knockout mice provide insights into hepatic handling of bilirubin, bile acids, and drugs. J Clin Invest 2010, 120:2942-2952

38. Keppler D: The roles of MRP2, MRP3, OATP1B1, and OATP1B3 in conjugated hyperbilirubinemia. Drug Metab Dispos 2014, 42:561-565

39. Chen ZS, Tiwari AK: Multidrug resistance proteins (MRPs/ABCCs) in cancer chemotherapy and genetic diseases. FEBS J 2011, 278:3226-3245

40. Arrese M, Trauner M: Molecular aspects of bile formation and cholestasis. Trends Mol Med 2003, 9:558-564

41. Fouassier L, Kinnman N, Lefevre G, Lasnier E, Rey C, Poupon R, Elferink RP, Housset C: Contribution of mrp2 in alterations of canalicular bile formation by the endothelin antagonist bosentan. J Hepatol 2002, 37:184-191

42. Wagner M, Zollner G, Trauner M: Nuclear receptor regulation of the adaptive response of bile acid transporters in cholestasis. Semin Liver Dis 2010, 30:160-177

43. Claudel T, Zollner G, Wagner M, Trauner M: Role of nuclear receptors for bile acid metabolism, bile secretion, cholestasis, and gallstone disease. Biochim Biophys Acta 2011, 1812:867-878

44. Chen F, Ghosh A, Shneider BL: Phospholipase D2 mediates signaling by ATPase class I type 8B membrane 1. J Lipid Res 2013, 54:379-385
45. Bruurs LJ, Donker L, Zwakenberg S, Zwartkruis FJ, Begthel H, Knisely AS, Posthuma G, van de Graaf SF, Paulusma CC, Bos JL: ATP8B1-mediated spatial organization of Cdc42 signaling maintains singularity during enterocyte polarization. J Cell Biol 2015, 210: $1055-1063$

46. McConkey M, Gillin H, Webster CR, Anwer MS: Cross-talk between protein kinases Czeta and B in cyclic AMP-mediated sodium taurocholate co-transporting polypeptide translocation in hepatocytes. J Biol Chem 2004, 279:20882-20888

47. Sarkar S, Bananis E, Nath S, Anwer MS, Wolkoff AW, Murray JW: PKCzeta is required for microtubule-based motility of vesicles containing the ntcp transporter. Traffic 2006, 7:1078-1091

48. Stross C, Keitel V, Winands E, Haussinger D, Kubitz R: Expression and localization of atypical PKC isoforms in liver parenchymal cells. Biol Chem 2009, 390:235-244

49. Hofmann M, Zgouras D, Samaras P, Schumann C, Henzel K, Zimmer G, Leuschner U: Small and large unilamellar vesicle membranes as model system for bile acid diffusion in hepatocytes. Arch Biochem Biophys 1999, 368:198-206

50. Fickert P, Zollner G, Fuchsbichler A, Stumptner C, Pojer C, Zenz R, Lammert F, Stieger B, Meier PJ, Zatloukal K, Denk H, Trauner M: Effects of ursodeoxycholic and cholic acid feeding on hepatocellular transporter expression in mouse liver. Gastroenterology 2001, 121: $170-183$

51. Yabas M, Jing W, Shafik S, Broer S, Enders A: ATP11C facilitates phospholipid translocation across the plasma membrane of all leukocytes. PLoS One 2016, 11:e0146774 